\title{
LAVA FLOW MONITORING USING TET-1 SATELLITE
}

\author{
K. Zakšek ${ }^{\mathrm{a}, *}$, E. Lorenz ${ }^{\mathrm{b}}$, M. Hort ${ }^{\mathrm{a}}$ \\ ${ }^{a}$ University of Hamburg, CEN, Institute of Geophysics, Bundesstr. 55, 20146 Hamburg, Germany - \\ klemen.zaksek@uni-hamburg.de, matthias.hort@uni-hamburg.de \\ ${ }^{\mathrm{b}}$ German Aerospace Center, Optical Information Systems, Rutherfordstraße 2, D-12489 Berlin, Germany - eckehard.lorenz@dlr.de
}

KEY WORDS: Volcanic Thermal Anomalies, Lava Flow, Stromboli, Small Satellites, TET-1

\begin{abstract}
:
Lava flow monitoring using satellites provides information on the temporal evolution of volcanic activity. It is usually done using metrological satellites because of the lack of more suitable satellites. The advantage of many meteorological satellites is the availability of appropriate spectral bands. For lava flow monitoring are most useful data in spectrum 3-4 $\mu \mathrm{m}$ (MIR) and 9-12 $\mu \mathrm{m}$ (TIR). However, the spatial resolution of meteorological satellites is usually very coarse causing uncertainties in results. Here we present the first long term satellite monitoring of an active lava flow on Stromboli volcano (end of August till the beginning of November 2014) in high spatial resolution $(160 \mathrm{~m})$ and relatively high temporal resolution ( 3 days). We analysed data from a test satellite TET-1, which is a test satellite developed at DLR. It carries an instrument dedicated to monitoring of high temperature events. MIR band observations are often saturated at the meteorological satellites. This is not the case of TET-1, although their spatial resolution is very fine for a thermal sensor. TET-1 retrieved 27 datasets over Stromboli during its effusive activity. Some of images were cloudy situations, but most of them were very useful for monitoring of the lava flow radiant power.
\end{abstract}

\section{INTRODUCTION}

Volcano thermal anomalies are due to increase in geothermal heat flux during the emplacement of shallow intrusions or subareal lava flows. Variations in the amount of radiated heat tell us much about volcanic processes. Lava lakes and lava flows have typical temperatures in the range of $400 \mathrm{~K}$ to $1000 \mathrm{~K}$ (Simkin and Siebert, 1994). According to Wien's displacement law the peak emission of the radiance for blackbody surfaces at such temperatures is between 3 and $5 \mu \mathrm{m}$ (i.e. in the medium infrared - MIR). For a temperature of $300 \mathrm{~K}$, which is the expected temperature to be measured by earth orbiting radiometers, the peak of the radiance emission is located at approximately $10 \mu \mathrm{m}$ (i.e. in the thermal infrared spectrum TIR).

The Earth orbiting radiometers measure spectral radiance at different wavelengths. It is straightforward to convert the spectral radiance to temperature (Planck's law) if the measured surface is isothermal at the pixel scale. The surface of an active volcano is, however, composed of lava crust of different ages, fresh lava, vegetation, water, etc. Considering Wien's law it is possible to detect thermal anomalies that usually cover only a small part of a single sensors' pixel area. The following example shows the differences in MIR/TIR sensitivities: a lava lake at $800 \mathrm{~K}$ covers $10 \%$ of the pixel area and the background temperature equals $300 \mathrm{~K}$; an observation at $4 \mu \mathrm{m}$ results in a brightness temperature of $530 \mathrm{~K}$ and an observation at $11 \mu \mathrm{m}$ results in only $390 \mathrm{~K}$.

This difference in sensitivities of different parts of spectrum on different temperatures resulted in different applications of remote sensing in volcanology (Coppola et al., 2009; Davies et al., 2008; Dehn et al., 2000; Harris et al., 2007, 1995; Lombardo et al., 2006; Oppenheimer and Francis, 1997; Pergola et al., 2004; Rothery et al., 1988; Wright et al., 2002; Wright and Pilger, 2008). The detected thermal anomalies are usually quantified by their temperature, area, radiant power
$(R P)$, or effusion rate. The uncertainty of these parameters is, however, difficult to estimate because of lack of redundant/repeated measurements (Zakšek et al., 2013). The uncertainty of the single measured spectral radiances depends on many reasons such as different sensor point spread and spectral response functions, different time of overpass, orbit geometry, and spatial resolution.

The largest source of uncertainties in thermal anomaly monitoring originates from the lack of suitable satellite instruments. A satellite instrument, which would be dedicated to monitoring of thermal anomalies, should have the following characteristics:

- fine spatial resolution (width of an average lava flow width $;<50 \mathrm{~m}$ ),

- $\quad$ short revisit time $(<15 \mathrm{~min})$,

- many spectral bands, or having an appropriate combination of bands (Lombardo et al., 2012),

- high radiometric accuracy $(<0.1 \mathrm{~K})$,

- possibility to observe at different instrument gain settings (being able to observe high and low temperature events).

It is impossible to provide such an instrument using the currently available technology. It is already necessary to make a compromise between spatial and temporal resolution - if the data are available in high temporal resolution (from geostationary instruments), it is impossible to provide high spatial resolution as well. The most promising seems a constellation of small satellites that can provide data at high spatial resolution; at the same time is the revisit time short because of high number of satellites in the constellation.

But other compromises have to be done as well. It is difficult to provide very narrow spectral bands at high radiometric accuracy for monitoring of high and low temperature at the same time. In remote sensing of volcanic thermal anomalies we usually use instruments designed for meteorological applications. These

\footnotetext{
* Corresponding author
} 
instruments contain also a MIR band, which provides the crucial data for monitoring of active volcanoes.

However, the settings of metrological instruments are optimized for monitoring of low temperatures. Therefore, the data retrieved by meteorological instruments over active volcanoes are often saturated. The saturation level depends on, besides the instrument's settings, also on the temperature of the observed anomaly and its size. Assuming that a typical volcanic thermal anomaly has a limited maximal temperature, the saturation of the signal at the instrument depends on the size of an anomaly. This means that the instruments with coarser spatial resolution are less prone to saturation than fine resolution instruments. However, fine resolution instruments are necessary to observe the exact position of the anomaly, which is not possible using instruments with a coarse resolution.

Currently operational instruments with spatial resolution of not more than $100 \mathrm{~m}$ are 1) the Operational Land Imager accompanied by the Thermal Infrared Sensor on-board Landsat8 and 2) the Advanced Spaceborne Thermal Emission and Reflection Radiometer on-board Terra satellite (has a malfunction in its short-wave infrared bands since spring 2008, which limits its use for the quantification of thermal anomalies). An alternative is also the Visible Infrared Imaging Radiometer Suite that provides a suitable spectral band (VIIRS I4) also at $375 \mathrm{~m}$ spatial resolution, but this band saturates already at $367 \mathrm{~K}$ (Schroeder et al., 2014).

Therefore, no satellite really suitable for volcanic thermal anomaly is at the moment operational. The gap between the available meteorological satellites and requirements by the volcanological community was partially closed by the test satellite TET-1 (German abbreviation for "Technologieerprobungsträger 1" meaning Technology Experiment Carrier). This is a microsatellite operated by the German Aerospace Center (DLR). TET-1 is based on the satellite bus used for the BIRD satellite, which was launched in 2001 (Briess et al., 2003). Here we will give just two important specifications of TET-1:

- it has finer spatial resolution than VIIRS $(\sim 160 \mathrm{~m})$ in MIR and TIR bands,

- its on-board processing allows repeated acquisition over the same area within some microseconds preventing data saturation.

For further details of the TET-1 mission see article titled Data Validation and Case Studies using the TET-1 Thermal Infrared Satellite System by C. Fischer et al., published on the same ISRSE36 conference.

In the following, we present the processing chain of TET-1 data in section 2. In section 3, we describe the effusive activity at Stromboli volcano in late summer of 2014 as seen by thermal images. In the end we discuss the results in section 4.

\section{PROCESSING OF TET-1 DATA}

We do not go into standard pre-processing methods here, but we focus on 1) georeferencing the data, and 2) estimation of the radiant power $(R P)$.

\subsection{Inter-band co-registration and georeferencing}

The first issue we noticed by the visual inspection of TET-1 data was its geolocation uncertainty. It can be larger than $10 \mathrm{~km}$. Each band is recorded with its own camera causing additional uncertainties in inter-band georeference. This means that each band is georoeferenced separately meaning that the MIR and TIR pixels are not appropriately co-registered. The same problem remains also for the data in the visible (red and green band) and near infrared spectrum (in the following abbreviated by VNIR; these three bands have $\sim 40 \mathrm{~m}$ spatial resolution).

The clouds may cover a large fraction of acquired images, thus they play a major role in the georeferencing of new images. Automatic inter-band co-registration is additionally difficult because of different spectral signatures of clouds. For instance, clouds reflect a large amount of solar insolation, thus they appear to be bright in VNIR images. Even in MIR spectrum they appear to be bright during daytime. Clouds are cooler than underlying sea/land, thus in night-time MIR images, they seem darker than land. This is because during the night the recorded signal corresponds only to the emitted radiance and not at all to its reflected radiance, so it corresponds to the object temperature. Because of this reason, clouds always seem dark in TIR bands as well, which is insensitive on solar insolation.

To reduce the effect of different spectral signatures of clouds, we computed for each band its gradient. Gradients are a first order derivate of the surface (image) and show only a relative change between neighbour pixels. Gradients expose different edges, for instance an edge between a cloud and the sea, an edge between the sea and the land, etc. Such edges are in general alike in all bands. Instead of using a gradient, some more sophisticated filter can be used, as for instance Sobel filter.

The inter-band co-registration was done in two steps using FFT based algorithm for automatic image registration (Xie et al., 2003). As the template we used MIR data, so we adjusted the location of data from other bands to MIR. The first step was done by co-registering the whole dataset at the original MIR/TIR resolution, thus the VNIR data were aggregated to this resolution as well. This provided a coarse inter band coregistration.

In the second step, we selected only the vicinity of volcano. These data were projected to the UTM projection in $40 \mathrm{~m}$ spatial resolution using nearest neighbours method. This combination was chosen to:

- overlap VNIR data with MIR/TIR on the pixel basis,

- preserve the radiometric values in MIR/TIR bands,

- at the same time preserve the geometry of MIR/TIR pixels.

The projected data were again co-registered using the same FFT based algorithm (Xie et al., 2003). The final accuracy of this automatic co-registration was in most cases approximately 1 MIR/TIR pixel large, but it can be worse in very cloudy conditions.

\subsection{Estimation of radiant power}

The most robust quantification of a thermal anomaly, which can be compared also among various instruments, is the total radiant power (Glaze et al., 1989). Radiant power $(R P)$ is also one of the parameters needed to estimate lava effusion rates during effusive eruptions and magma flux rates at active lava lakes (Harris et al., 1997; Wright et al., 2001). RP can be estimated from eq. 1 (Glaze et al., 1989):

$$
R P=A \cdot \varepsilon \cdot \sigma \cdot \sum f_{i} \cdot T_{i}^{4}
$$

$$
\begin{array}{ll}
\text { where } \quad & A-\text { the pixel area } \\
& \varepsilon-\text { the emissivity } \\
& \sigma-\text { the Stefan-Boltzmann's constant } \\
& f_{i}-\text { the part of the pixel having temperature } T_{i}, \\
& T-\text { temperature }
\end{array}
$$


Large errors in area and temperatures of each sub-pixel component are possible (Giglio and Kendall, 2001), thus Kaufman et al. (1998) proposed a semi-empirical method based on a relationship between $R P$ and brightness temperature in the MIR spectrum. Wooster et al. (2003) further showed that it is possible to estimate $R P$ also directly from unsaturated radiances in the MIR spectrum. They noticed that in the MIR spectrum the relationship between emitting temperatures and corresponding spectral radiances converges towards the relationship of Stefan-Boltzman law. For the temperature range where this is valid, the ratio between the total power emitted at all wavelengths to the power emitted in MIR spectrum is approximately constant. This makes the method robust: only the MIR radiance of the thermal anomaly and its background is needed; emissivity is not required. The method was developed for MODIS and BIRD data (Wooster et al., 2003); see eq. 2:

$$
R P=k \cdot\left(L_{M I R}-L_{\text {MIRbg }}\right)
$$

where $\quad k-$ a coefficient unique to each instrument (depends on its response function and its spatial resolution) $L_{M I R}$ - the spectral radiance of the detected thermal anomaly in MIR band

$L_{\text {MIRbg }}$ - the spectral radiance of the background in MIR band

We have followed a similar approach. We have fitted a curve ( $4^{\text {th }}$ power of temperature; fig. 1) between 600 and $1500 \mathrm{~K}$, for the middle wavelength of TET-1 MIR band $3.8 \mu \mathrm{m}$ and $40 \mathrm{~m}$ spatial resolution. The estimated $k$ equals $3.32 \cdot 10^{4} \mathrm{~m}^{2} \mathrm{sr} \mu \mathrm{m}$. As it is seen from fig. 1, this method overestimates $R P$ under areas of $700 \mathrm{~K}$, but then it tends to underestimate them on volcanic features of higher temperatures.

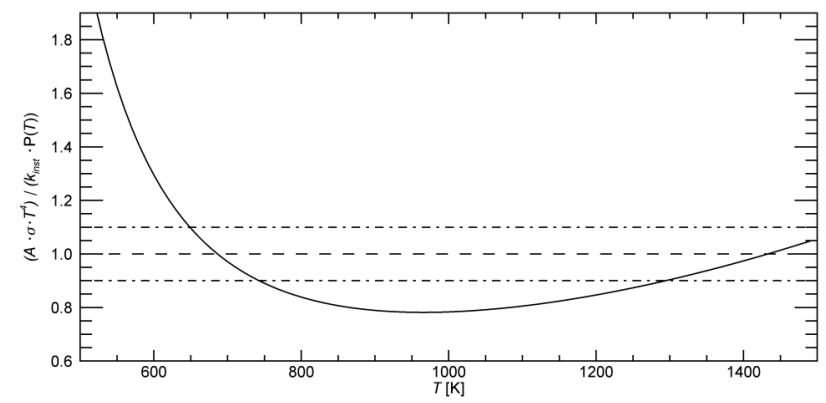

Figure 1. Ratio between the true radiant power and the estimation by Wooster et al. (2003)

\section{EFFUSIVE ACTIVITY OF STROMBOLI IN 2014}

Stromboli is a small volcanic island in the Tyrrhenian Sea. It belongs to a volcanic arc north of Sicily. The volcano has been constantly active for the last 2000 years. Its eruptions, often visible from many points on the island and from the surrounding sea, gave the island a nickname "Lighthouse of the Mediterranean" (Tinti et al., 2005). Stromboli rises $926 \mathrm{~m}$ above sea level and almost $3000 \mathrm{~m}$ above the sea floor. On the north side of the island, there is a significant geological feature named Sciara del Fuoco. It is a depression that has been generated by several collapses and lava flows.

Stromboli's usual behaviour can be described by explosions at the summit craters at intervals ranging from minutes to hours. Eruptions from the summit craters typically result in a few short, mild, but energetic bursts, ranging up to a few hundred meters in height, containing ash, incandescent lava fragments and stone blocks. Although it has mainly explosive activity, effusive activity was observed in the past as well. In the last years, an effusive eruption occurred in 2002 (Tinti et al., 2005), 2003 (Calvari et al., 2005; Harris et al., 2005; Ripepe et al., 2007, 2005; Rosi et al., 2006), 2007 (Ripepe et al., 2009), and 2013-14 (Rizzo et al., 2015).

The effusive activity presents no direct hazard to the inhabitants of the island. However, the effusive activity has been often followed by paroxysmic phases and these might cause a collapse in Sciara del Fuoco that can result in a tsunami (Tinti et al., 2005, 2003). In other words, effusive activity at Stromboli is an exceptional activity that can present a hazard to a wider area.

\subsection{Comparison between in-situ and TET-1 observations}

In September 2014, a team from the University of Hamburg, was working on an in-situ experiment at Stromboli volcano. We used cameras measuring in infrared spectrum along other instruments. One of both cameras measures irradiation in TIR spectrum (Infratec VarioCam HR with $30 \mathrm{~mm}$ lense) and the other in short-wave infrared (SWIR) and MIR (Infratec ImageIR with $25 \mathrm{~mm}$ lense).

Unfortunately, it was not possible to observe the whole lava flow because of geometrical restrictions. Usually, we could observe only the lowest part of the flow from the side. Our observation position was on the eastern side of the Sciara del Fuoco at the height of $290 \mathrm{~m}$. From there we could not see the vent producing the lava flow.

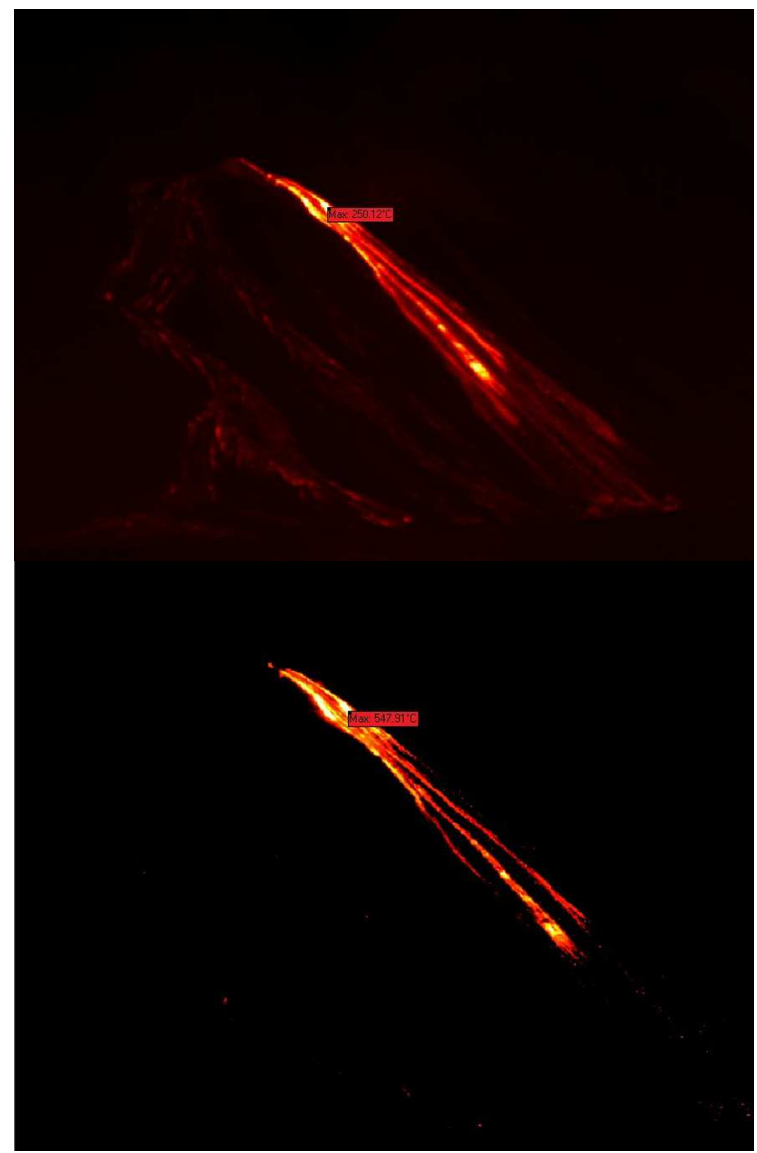

Figure 2. Observations with infrared cameras (TIR above, MIR below) from a boat in front of Sciara del Fuoco on Sep. 202014 around 19:50 UTC. 
A significantly better view on the lava flow was given from a boat (fig. 2) situated $\sim 2 \mathrm{~km}$ away from the lava flow, which means that the average pixel resolution was $1.2 \mathrm{~m}$. The estimated area of the lava flow was 2 ha. Because of the huge differences in the geometry between in-situ and satellite observations acquired almost two hours later, we compare here only the radiant power for pixels recognizes as thermal anomalies according to MODVOLC algorithm (Wright et al, 2002, 2004). Satellite based estimations resulted into $50 \mathrm{MW}$ and in-situ into $R P$ of $80 \mathrm{MW}$. The difference in $R P$ is significant but it can be attributed also to the difference in the acquisition time. Fig. 3 shows 18 processed observations (MIR band only). Another 9 datasets were acquired but these situations were mostly too cloudy to be usable.

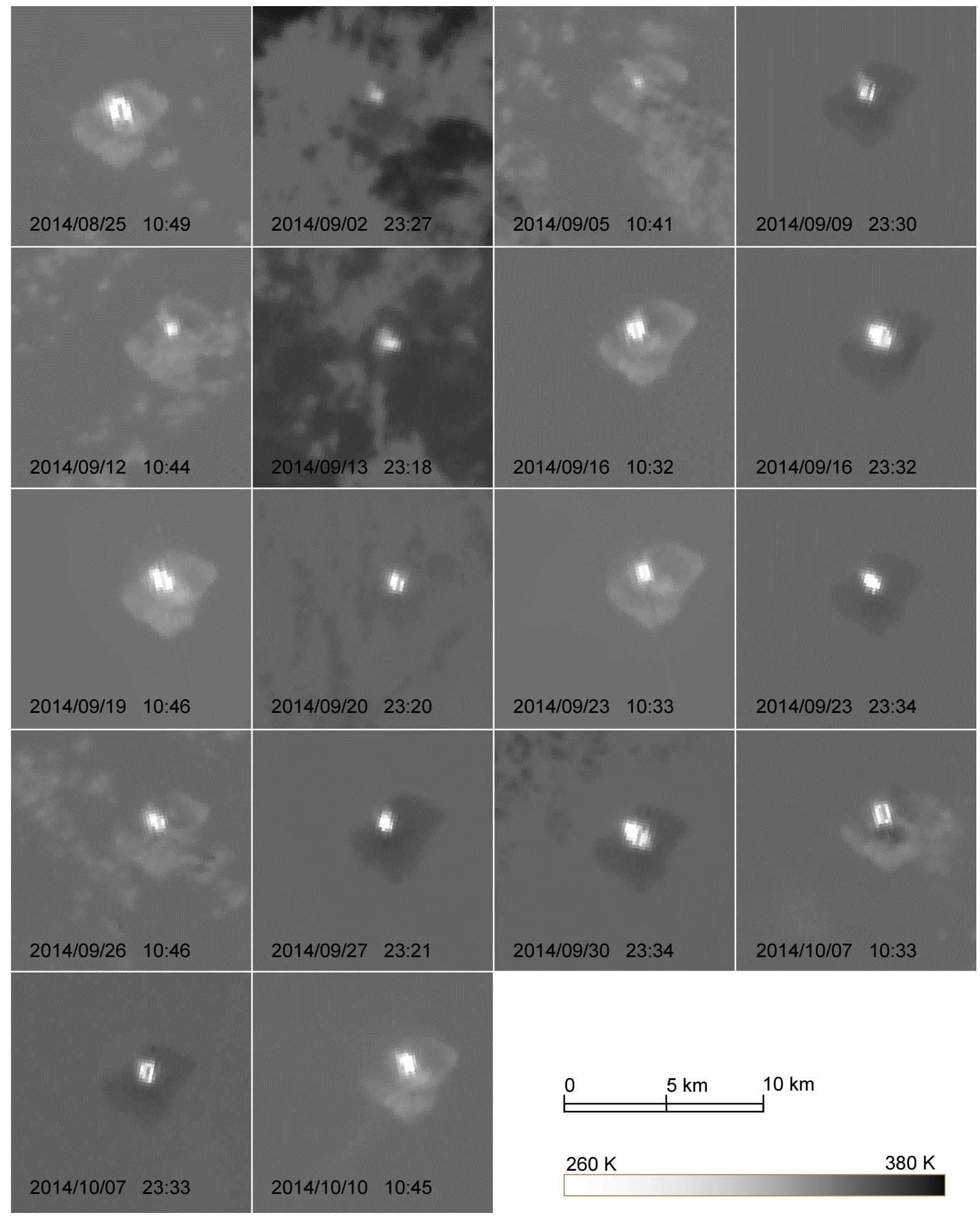

Fig. 3. Brightness temperature (range 260-380 K) from TET-1 data; time is given in UTC. Land is darker (cooler) on night images, sea has almost constant temperature, and clouds appear very cool as well. The brightest (hottest) areas correspond to lava flow, which is on the peak divided into two flows (see also fig. 2). 


\subsection{Comparison between MODVOLC and TET-1 observations}

We compared TET-1 data also to the data retrieved by MODIS (fig. 3). MODIS radiant power was computed from MODVOLC database (Wright et al., 2004, 2002) using Wooster's method (2003). MODIS provides usually four datasets per day, but its radiant power is in general smaller than from TET-1. The reason for this bias is most likely spatial resolution - MODIS sees $\sim 40$ times less detail than TET-1. This makes TET-1 as a most valuable tool for volcano hotspots monitoring.

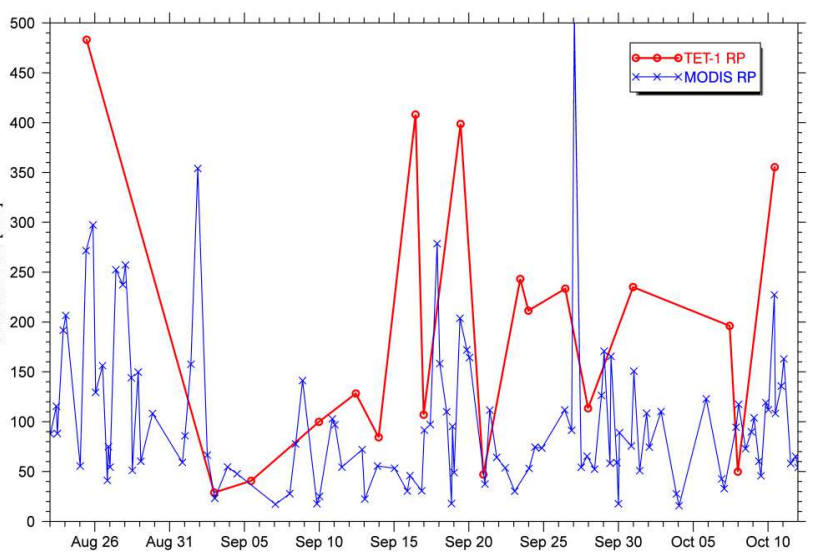

Fig. 4. Comparison of radiant power estimated from TET-1 and MODIS data. TET-1 provides in general higher values due to its finer resolution but its observations are less frequent

\section{DISCUSSION AND CONCLUSIONS}

Observations of effusive volcanic activity in high spatial resolution and relatively short revisit time were not possible until recently as TET-1 became operational. Even more important, most instruments, which are usually used for such observations, tend to saturate in the case of intensive volcanic activity. Some methods have been developed that try to correct the saturation by observing a longer time series of data (Barnie et al., 2015). However, this procedure is suitable only for geostationary data, which have coarse spatial resolution.

TET-1 does indeed have much better spatial resolution than most of satellite instruments being used in volcanology, as for instance MODIS. TET- 1 can for instance also see the separated signal peaks on the top of Stromboli. However, the presented images still seem blurred. This prevents more detailed analysis on the extent of the lava flow, which is extremely important for modelling the evolution of the flow. This means that we should put more effort in the future in deconvolution of the data. For that it is necessary to know the precise point spread function of the instrument and in-situ data for validation of results.

\section{ACKNOWLEDGEMENTS}

The research has been supported by grants from the German Science Foundation (DFG) number ZA659/1-1.

The TET-1 data were obtained thorough personal communication with E. Lorenz (German Aerospace Centre DLR).

\section{REFERENCES}

Barnie, T., Oppenheimer, C., 2015. Extracting High Temperature Event radiance from satellite images and correcting for saturation using Independent Component Analysis. Remote Sensing of Environment 158, 56-68. doi:10.1016/j.rse.2014.10.023

Briess, K., Jahn, H., Lorenz, E., Oertel, D., Skrbek, W., Zhukov, B., 2003. Fire recognition potential of the bi-spectral Infrared Detection (BIRD) satellite. Int. J. Remote Sens. 24, 865-872. doi:10.1080/01431160210154010

Calvari, S., Spampinato, L., Lodato, L., Harris, A.J.L., Patrick, M.R., Dehn, J., Burton, M.R., Andronico, D., 2005. Chronology and complex volcanic processes during the 2002 2003 flank eruption at Stromboli volcano (Italy) reconstructed from direct observations and surveys with a handheld thermal camera. J. Geophys. Res. Solid Earth 110, B02201. doi:10.1029/2004JB003129

Coppola, D., Piscopo, D., Staudacher, T., Cigolini, C., 2009. Lava discharge rate and effusive pattern at Piton de la Fournaise from MODIS data. J. Volcanol. Geotherm. Res. 184, 174-192. doi:10.1016/j.jvolgeores.2008.11.031

Davies, A.G., Calkins, J., Scharenbroich, L., Vaughan, R.G., Wright, R., Kyle, P., Castańo, R., Chien, S., Tran, D., 2008. Multi-instrument remote and in situ observations of the Erebus Volcano (Antarctica) lava lake in 2005: A comparison with the Pele lava lake on the jovian moon Io. J. Volcanol. Geotherm. Res. 177 705-724.

Dehn, J., Dean, K., Engle, K., 2000. Thermal monitoring of North Pacific volcanoes from space. Geology 28, 755-758. doi:10.1130/0091-7613(2000)28<755:TMONPV>2.0.CO;2

Giglio, L., Kendall, J.D., 2001. Application of the Dozier retrieval to wildfire characterization: a sensitivity analysis. Remote Sens. Environ. 77, 34-49. doi:10.1016/S00344257(01)00192-4

Glaze, L., Francis, P.W., Rothery, D.A., 1989. Measuring thermal budgets of active volcanoes by satellite remote sensing. Nature 338, 144-146. doi:10.1038/338144a0

Harris, A., Dehn, J., Patrick, M., Calvari, S., Ripepe, M., Lodato, L., 2005. Lava effusion rates from hand-held thermal infrared imagery: an example from the June 2003 effusive activity at Stromboli. Bull. Volcanol. 68, 107-117. doi:10.1007/s00445-005-0425-7

Harris, A.J.L., Blake, S., Rothery, D.A., Stevens, N.F., 1997. A chronology of the 1991 to 1993 Mount Etna eruption using advanced very high resolution radiometer data: Implications for real-time thermal volcano monitoring. J. Geophys. Res. 102, 7985-8003. doi:199710.1029/96JB03388

Harris, A.J.L., Dehn, J., Calvari, S., 2007. Lava effusion rate definition and measurement: a review. Bull. Volcanol. 70, 1-22. doi:10.1007/s00445-007-0120-y 
Harris, A.J.L., Swabey, S.E.J., Higgins, J., 1995. Automated thresholding of active lavas using AVHRR - data. Int. J. Remote Sens. 16, 3681-3686. doi:10.1080/01431169508954654

Kaufman, Y.J., Justice, C.O., Flynn, L.P., Kendall, J.D., Prins, E.M., Giglio, L., Ward, D.E., Menzel, W.P., Setzer, A.W., 1998. Potential global fire monitoring from EOS-MODIS. J. Geophys. $\quad$ Res. 32215-32238. doi:199810.1029/98JD01644

Lombardo, V., Buongiorno, M., Amici, S., 2006. Characterization of volcanic thermal anomalies by means of sub-pixel temperature distribution analysis. Bull. Volcanol. 68, 641-651. doi:10.1007/s00445-005-0037-2

Lombardo, V., Musacchio, M., Buongiorno, M.F., 2012. Error analysis of subpixel lava temperature measurements using infrared remotely sensed data. Geophys. J. Int. 191, 112-125. doi:10.1111/j.1365-246X.2012.05632.x

Oppenheimer, C., Francis, P., 1997. Remote sensing of heat, lava and fumarole emissions from Erta 'Ale volcano, Ethiopia. Int. J. Remote Sens. 18, 1661-1692. doi: $10.1080 / 014311697218043$

Pergola, N., Marchese, F., Tramutoli, V., 2004. Automated detection of thermal features of active volcanoes by means of infrared AVHRR records. Remote Sens. Environ. 93, 311-327. doi:10.1016/j.rse.2004.07.010

Ripepe, M., Delle Donne, D., Lacanna, G., Marchetti, E., Ulivieri, G., 2009. The onset of the 2007 Stromboli effusive eruption recorded by an integrated geophysical network. J. Volcanol. Geotherm. Res., The 2007 Eruption of Stromboli 182, 131-136. doi:10.1016/j.jvolgeores.2009.02.011

Ripepe, M., Marchetti, E., Ulivieri, G., 2007. Infrasonic monitoring at Stromboli volcano during the 2003 effusive eruption: Insights on the explosive and degassing process of an open conduit system. J. Geophys. Res. Solid Earth 112, B09207. doi:10.1029/2006JB004613

Ripepe, M., Marchetti, E., Ulivieri, G., Harris, A., Dehn, J., Burton, M., Caltabiano, T., Salerno, G., 2005. Effusive to explosive transition during the 2003 eruption of Stromboli volcano. Geology 33, 341-344. doi:10.1130/G21173.1

Rizzo, A.L., Federico, C., Inguaggiato, S., Sollami, A., Tantillo, M., Vita, F., Bellomo, S., Longo, M., Grassa, F., Liuzzo, M., 2015. The 2014 effusive eruption at Stromboli volcano (Italy): inferences from soil $\mathrm{CO} 2$ flux and $3 \mathrm{He} / 4 \mathrm{He}$ ratio in thermal waters. Geophys. Res. Lett. 2014GL062955. doi:10.1002/2014GL062955

Rosi, M., Bertagnini, A., Harris, A.J.L., Pioli, L., Pistolesi, M., Ripepe, M., 2006. A case history of paroxysmal explosion at Stromboli: Timing and dynamics of the April 5, 2003 event. Earth Planet. Sci. Lett. 243, 594-606. doi:10.1016/j.epsl.2006.01.035

Rothery, D.A., Francis, P.W., Wood, C.A., 1988. Volcano Monitoring Using Short Wavelength Infrared Data from Satellites. J. Geophys. Res. 93, 7993-8008.
Schroeder, W., Oliva, P., Giglio, L., Csiszar, I.A., 2014. The New VIIRS $375 \mathrm{~m}$ active fire detection data product: Algorithm description and initial assessment. Remote Sens. Environ. 143, 85-96. doi:10.1016/j.rse.2013.12.008

Simkin, T., Siebert, L., 1994. Volcanoes of the World: A Regional Directory, Gazetteer, and Chronology of Volcanism During the Last 10,000 Years, 2 Sub. ed. Geoscience Press, Tucson, USA.

Tinti, S., Maramai, A., Armigliato, A., Graziani, L., Manucci, A., Pagnoni, G., Zaniboni, F., 2005. Observations of physical effects from tsunamis of December 30, 2002 at Stromboli volcano, southern Italy. Bull. Volcanol. 68, 450-461. doi:10.1007/s00445-005-0021-x

Tinti, S., Pagnoni, G., Zaniboni, F., Bortolucci, E., 2003. Tsunami generation in Stromboli island and impact on the south-east Tyrrhenian coasts. Nat. Hazards Earth Syst. Sci. 3, 299-309.

Wooster, M.J., Zhukov, B., Oertel, D., 2003. Fire radiative energy for quantitative study of biomass burning: derivation from the BIRD experimental satellite and comparison to MODIS fire products. Remote Sens. Environ. 86, 83-107. doi:10.1016/S0034-4257(03)00070-1

Wright, R., Blake, S., Harris, A.J.L., Rothery, D.A., 2001. A simple explanation for the space-based calculation of lava eruption rates. Earth Planet. Sci. Lett. 192, 223-233. doi:10.1016/S0012-821X(01)00443-5

Wright, R., Flynn, L., Garbeil, H., Harris, A., Pilger, E., 2002. Automated volcanic eruption detection using MODIS. Remote Sens. Environ. 82, 135-155. doi:10.1016/S00344257(02)00030-5

Wright, R., Flynn, L.P., Garbeil, H., Harris, A.J.L., Pilger, E., 2004. MODVOLC: near-real-time thermal monitoring of global volcanism. J. Volcanol. Geotherm. Res. 135, 29-49. doi:10.1016/j.jvolgeores.2003.12.008

Wright, R., Pilger, E., 2008. Radiant flux from Earth's subaerially erupting volcanoes. Int. J. Remote Sens. 29, 64436466. doi:10.1080/01431160802168210

Xie, H., Hicks, N., Randy Keller, G., Huang, H., Kreinovich, V., 2003. An IDL/ENVI implementation of the FFT-based algorithm for automatic image registration. Comput. Geosci. 29, 1045-1055. doi:10.1016/S0098-3004(03)00104-3

Zakšek, K., Shirzaei, M., Hort, M., 2013. Constraining the uncertainties of volcano thermal anomaly monitoring using a Kalman filter technique. Geol. Soc. Lond. Spec. Publ. 380, 137-160. doi:10.1144/SP380.5 